\title{
Evaluation of typical wma additives on design parameters of SMA mixtures
}

Bekir Aktaş (Main and Corresponding Author)

Department of Civil Engineering, Faculty of Engineering, Erciyes University

38039 Melikgazi, Kayseri (Turkey)

baktas@erciyes.edu.tr

Şuayip Aytekin

6th Regional Directorate of the General Directorate of Highways

38060 Melikgazi, Kayseri (Turkey)

saytekin@kgm.gov.tr

Şevket Aslan

Department of Civil Engineering, Faculty of Engineering, Erciyes University

38039 Melikgazi, Kayseri (Turkey)

sevketaslan@erciyes.edu.tr

Manuscript Code: 1155

Date of Acceptance/Reception: 29.08.2019/21.07.2018

DOI: 10.7764/RDLC.18.3.409

\begin{abstract}
Warm Mix Asphalt (WMA) technologies have made a considerable development in recent years, where studies on environmental pollution and protection of natural resources have become prominent all over the world. Thanks to the rapidly developing and renewed WMA technologies, nonrenewable resources can be saved while environmental effects caused by asphalt production can be reduced. In recent years, WMA technologies have begun to gain importance in the production of Hot Mix Asphalt (HMA), particularly in developing countries where energy supplying is quite expensive for economic reasons. In this study, Stone Mastic Asphalt (SMA) was produced by using pure and modified bitumen with three different WMA admixtures. Marshall tests were carried out to examine the design parameters of these samples. As a result, Marshall Design parameters of Warm Mix Stone Mastic Asphalt (WM-SMA) blends have been produced with WMA additives by decreasing the construction temperature. The resulting mixtures fall within specification criteria.
\end{abstract}

Keywords: Warm Mix Asphalt, stone mastic asphalt, hot mix asphalt, additives, energy efficiency.

Introduction

Asphalt mixtures, which generally contain aggregate and bitumen, are commonly used materials in the construction of road pavements. The performance of the asphalt mixtures depends on the quality of each material and their interaction. The production of an asphalt mixture with high durability is related to its sustainability. Higher durability results in a better use of energy resources during production and replacement (Valdés, Miró, \& Martínez, 2015; Valdés Vidal, CalabiFloody, \& Sanchez-Alonso, 2017).

The stone mastic asphalt mixture with gap-graded design is obtained by filling the voids in the coarse aggregate frame with bitumen-filler mortar. The SMA mixture is resistant to the formation of tire tracks and has high durability due to its high bitumen ratio. Fiber, polymers, or both, are usually used to prevent bituminous drainage during the production and application of stone mastic (Hafeez, Kamal, \& Mirza, 2015; Kok \& Akpolat, 2015; Kok, Yilmaz, \& Erkus, 2017; Oluwasola \& Hainin, 2016; Woodward, Millar, Lantieri, Sangiorgi, \& Vignali, 2016). SMA mixtures are widely used all over the world due to many advantages they provide. It has been observed that structural resistance and skid resistance increase as well as resistance against the rutting. It has also been observed that it increases sound absorption, longer duration of service and resistance to aging (Khedmati, Khodaii, \& Haghshenas, 2017; Vázquez, Terán, Luong, \& Paje, 2019; Wasilewska, 2017).

The use of warm mix asphalt (WMA) has been widely becoming more popular in the asphalt industry. WMA technology has many benefits such as global warming, air quality, and fuel needs. The most significant benefits of WMA are less pollution and lower energy consumption. Both the production and laying temperatures of the WMA process are lower than those of the HMA. This shows that the amount of emission they emit to the environment is lower. Therefore, WMA has little effect on the health of employees compared to HMA. In literature, it is identified as many as fifteen different 
WMA technologies currently available. The foaming or some chemical or organic additives are most commonly used for WMA technologies (Chowdhury \& Button, 2008).

The first development of WMA technology was in the 1990s. By WAM-Foam technology in Germany and Norway, the ingredients were investigated. WMA technologies were developed not only by the foam system but also by using wax cores and chemical additives. (Dubravský \& Mandula, 2015). The production temperature of WMA is in between $100{ }^{\circ} \mathrm{C}$ $-140{ }^{\circ} \mathrm{C}$ while the temperature range of Hot mix asphalt (HMA) is about $140-190^{\circ} \mathrm{C}$. Kim et al. studied the performance properties of SMA-WMA mixture using a wax-based WMA additive and compared with the conventional SMA mixture without an additive. Authors determined viscoelastic properties, moisture susceptibility, fatigue resistance, rutting resistance at high temperature, and crack resistance at a low temperature of both samples. They reported that WMA variants demonstrated better performance in these performance parameters in comparison to conventional SMA variants (Kim et al., 2015). In addition, SMA-WMA is more environmentally friendly than conventional SMA in terms of economic competition (Leng, Al-Qadi, \& Cao, 2017).

The main object of this study was to evaluate design and performance parameters of Warm SMA mixture along with the conventional SMA without additive according to the Highway Technical Specification (THS). SMA concrete samples produced with various WMA admixtures and Marshall tests method was applied to specimens. According to Marshall results, it is observed that the design parameters of SMA specimens are within the desired limits according to THS. WMSMA has been proved to be the potential of choice in the future when evaluated together with its other advantages. It is possible to see that the production and compression temperatures stated in the Highways Condition require higher temperatures than HMA. For this reason, it is possible to produce WM-SMA by using warm mix additives in order to reduce SMA production and compaction temperatures so that the mix design and quality standards meet the criteria of THS.

\section{Material and method}

\section{Materials}

Aggregate. Mineral aggregate used for SMA design supplied from Ucdam quarry located in Erzincan city in Turkey. It is desired that aggregates obtained from crushing of aggregate granite, basalt or other high-quality magmatic rocks shall be used in SMA mixtures according to Turkish Highways specifications (Turkey General Directorate of Highways, 2013). In this study, basalt type aggregate was used. When coarse aggregate gravel is produced, it is desirable that all faces of the aggregate are broken. SMA is a method that has been implemented commonly in recent years in Turkey. However, its cost level is higher and its application is more difficult than the traditional HMA like e.g. asphalt concrete. The properties of the aggregate are presented in Table 1. The granulometry curve for the aggregate is given in Figure 1.

Table 1. Properties of Aggregate. Source: Self-elaboration.

\begin{tabular}{lccc}
\multicolumn{4}{c}{ Table 1. Properties of Aggregate. Source: Self-elaboration. } \\
\hline Properties & Method (AASHTO,2004) & Requirement & Values \\
\hline Coarse Aggregate & & \\
Los Angeles abrasion (\%) & AASHTO T96 & 30 max. & 20 \\
Water absorption (\%) & AASHTO T85 & 5 max. & 0.85 \\
Bulk specific density (g/cm ${ }^{3}$ ) & AASHTO T85 & - & 2.821 \\
Flat and Elongated (3 to 1) (\%) & ASTM D4791 & 20 max. & 13 \\
Soundness (Sodium Sulfate) (\%) & AASHTO T104 & 15 max. & 5.1 \\
Crushed Content (One Face) (\%) & ASTM D5821 & 100 min. & 100 \\
Crushed Content (Two Face) (\%) & ASTM D5821 & 90 min. & 100 \\
Fine aggregate & & & \\
Water absorption (\%) & AASHTO T84 & - \\
Bulk specific density (g/cm ${ }^{3}$ ) & AASHTO T84 & - & 2.78 \\
\hline
\end{tabular}

Bitumen. As bituminous binder, 50/70 paving grade bitumen was provided from the TUPRAS refinery, İzmit, Turkey. In the production of SMA mixture, pure and by WMA additives modified bitumen were used. To compare physical properties of pure and modified bitumen, penetration test at $25^{\circ} \mathrm{C}$, specific gravity at $25^{\circ} \mathrm{C}$, softening point, rotational viscosity at $135^{\circ} \mathrm{C}$ (Pa.s) and ductility at $25^{\circ} \mathrm{C}(\mathrm{cm})$ were applied. Physical properties of the pure and by WMA additive modified bitumens are shown in Table 2. 


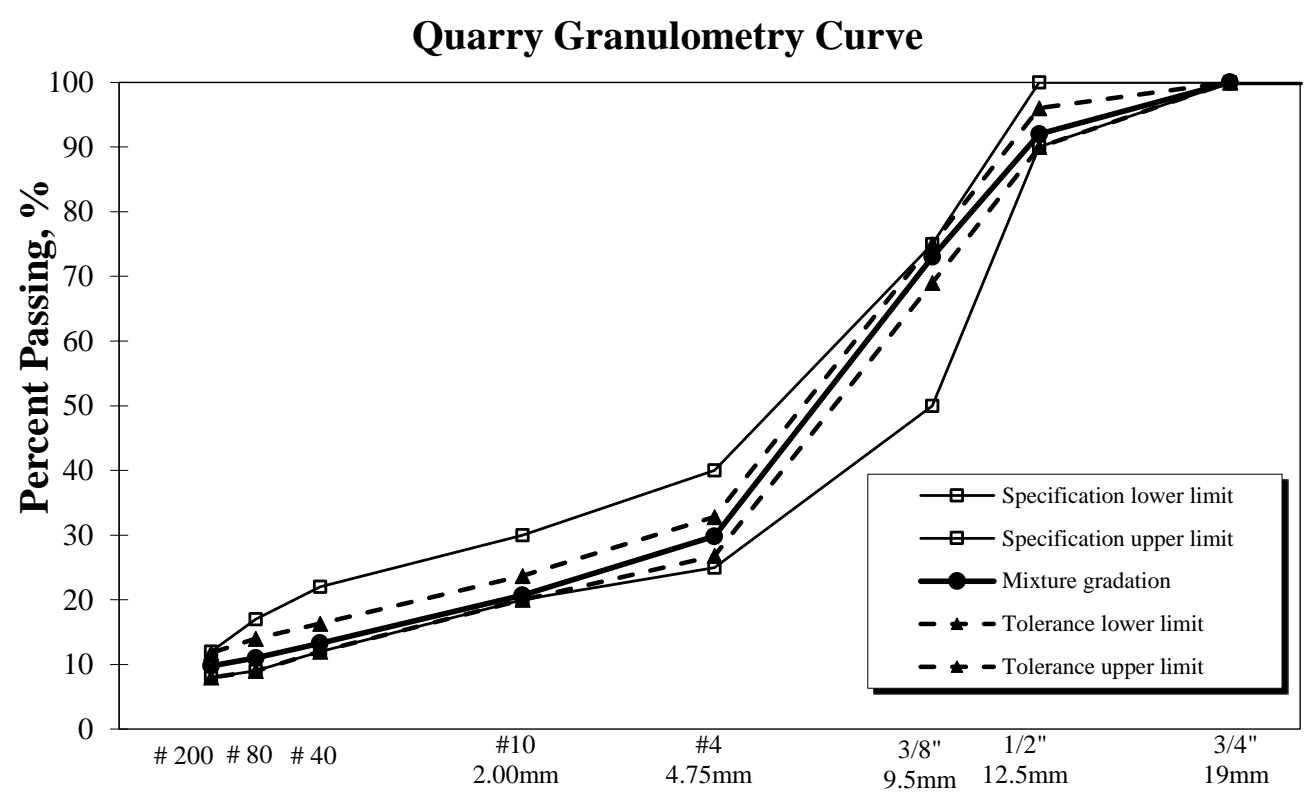

Sieve Diameters

Table 2. Physical properties of the pure and WMA additive binder. Source: Self-elaboration.

\begin{tabular}{lccccc}
\hline \multicolumn{1}{c}{ Table 2. Physical properties of the pure and WMA additive binder. Source: Self-elaboration. } \\
\cline { 3 - 6 } \multicolumn{1}{c}{ Parameter measured } & \multicolumn{4}{c}{ Test Value } \\
\cline { 3 - 6 } & $\begin{array}{c}\text { Test Method } \\
\text { (AASHTO, 2004) }\end{array}$ & $\begin{array}{c}\text { Pure } \\
\text { Bitumen } \\
50 / 70 \text { Pen }\end{array}$ & $\begin{array}{c}\text { A1 } \\
\text { Doped } \\
\text { Bitumen }\end{array}$ & $\begin{array}{c}\text { A2 } \\
\text { Doped } \\
\text { Bitumen }\end{array}$ & $\begin{array}{c}\text { A3 } \\
\text { Doped } \\
\text { Bitumen }\end{array}$ \\
\hline Specific gravity at $25^{\circ} \mathrm{C}\left(\mathrm{g} / \mathrm{cm}^{3}\right)$ & AASHTO T228 & 1.033 & 1.027 & 1.033 & 1.009 \\
Penetration at $25^{\circ} \mathrm{C}(0.1 \mathrm{~mm})$ & AASHTO T49 & 57.5 & 70 & 41 & 53 \\
Softening point $\left(\mathrm{R}\right.$ and B) $\left({ }^{\circ} \mathrm{C}\right)$ & AASHTO T53 & 49.08 & 50.04 & 80 & 50.2 \\
Viscosity at $135^{\circ} \mathrm{C}(\mathrm{Pa}-\mathrm{s})$ & AASHTO T201 & 0.71 & 0.49 & 0.35 & 0.45 \\
Ductility at $25^{\circ} \mathrm{C}(\mathrm{cm})$ & AASHTO T51 & $>100$ & 65 & 95 & 94 \\
\hline
\end{tabular}

Cellulose fibers are used in SMA mixtures to prevent the drain down problem of the binder. Cellulose fiber was added to SMA mixtures at the ratio of the $0.35 \%$ by the weight of the mixture.

Additives: Different commercial WMA additives were used for SMA production. PAWMA ${ }^{\oplus}$ (A1), Licomont BS $^{100}{ }^{\circ}$ (A2) and Evotherm $\mathrm{M1}^{\circ}(\mathrm{A} 3)$ additives were received from the producers and added to bitumen at the recommended rates according to producers' technical sheets.

A1 is a kind of amidoamine derivative additive produced by Istanbul Teknik Company. It provides that asphalt mixture has longer workability and that a better compaction of asphalt is obtained. The chemical description is given as hydrated alumina silicate of alkali metals. It is used before mixing with bitumen. According to the manufacturer, the bitumen temperature for the mixture is not changed, but the mixture is prepared by reducing the aggregate temperature by $30^{\circ} \mathrm{C}$. Usage amount is between $0.2 \%$ and $0.4 \%$ of the weight of the bitumen. Also, according to the manufacturer's recommendation, the dosage of the additive should be decided on site depending on the application type, whether or not the asphalt is modified, environmental conditions such as ambient temperature and wind. Since each application differs from the other, a standard dosage table is not available and the dosage should be determined according to local conditions. A1 additive is produced with amine compounds as well as anti-peeling additives. It affects the structure of the bitumen positively and does not disturb the chemical properties of bitumen. Asphalt increases peel strength and indirect tensile strength. Since it does not contain water as it is zeolite-based or foam-activated admixtures, there is no water sensitivity (Istanbulteknik, 2018).

A2, from manufacturer Clariant SE, is fatty acid amides wax. The product reduces the viscosity of molten asphalt and therefore allows improving workability, reducing the temperature during application, increasing stability at high temperatures without reducing the resistance to low temperatures, and increasing adhesion to aggregate. In lab applications, $3 \%$ of Licomont BS 100 bitumen is directly mixed with bitumen and mixed for about 40 minutes at $160{ }^{\circ} \mathrm{C}$. 
According to Turkish Highways Specifications (THS) the mixing temperature for SMA is $175^{\circ} \mathrm{C}$. Aggregates were heated to $150^{\circ} \mathrm{C}$ and mixed with Licomont-modified bitumen for 3-5 minutes. For the preparation of Marshall specimens, the production temperature of the mixture should be $155^{\circ} \mathrm{C} .90 \%$ of the compaction must be completed at $120^{\circ} \mathrm{C}$ and the rolling must be finished at $110{ }^{\circ} \mathrm{C}$ (Clariant, 2018).

A3, a warm asphalt admixture produced by MWV Co., is an additive type with an amine compound. It is introduced as a warm mix asphalt technology to improve the coating, increase adhesion between aggregate and binder, improve workability and compaction. It is also said that the HMA can also be used to increase the properties of the mixture in the production of asphalt. The use of this additive in HMA results in a temperature reduction by 15 to $30{ }^{\circ} \mathrm{C}$ compared to the conventional HMA. A3 additive requires a recommended ratio of $0.25-0.75 \%$ by bitumen weight in order to make sure the results that the producers of asphalt are trying to accomplish. In this study, A3 added to the bituminous binder at a ratio of $0.4 \%$ of the bitumen by weight and mixed for 30 minutes (Asphalt_Innovations, 2010).

\section{Method}

Marshall Design method was performed using a selected aggregate gradation and bitumen. Paving grade bitumen $50 / 70$ was modified using WMA additives as specified by the producer. SMA designs were made by Marshall method in accordance with Turkey General Directorate of Highways standards. In addition, the temperatures to be used in the mixture were determined as recommended by the manufacturers of additives.

\section{WM-SMA design}

In order to produce SMA samples, identical mixture design and Marshall parameters were applied for WM-SMA mixtures and conventional SMA mix. The Marshall Design criteria according to THS for the SMA design is given in Table 3.

Table 3. SMA Marshall Design Criteria (Turkey General Directorate of Highways, 2013).

\begin{tabular}{|c|c|c|c|c|}
\hline \multirow[b]{2}{*}{ Specifications } & & \multicolumn{2}{|c|}{ Specification Limits } & \multirow[b]{2}{*}{ Test Standard } \\
\hline & & $\begin{array}{c}\text { SMA } \\
\text { Wearing } \\
\text { Coarse }\end{array}$ & $\begin{array}{c}\text { SMA } \\
\text { Binder } \\
\text { Coarse }\end{array}$ & \\
\hline Number of Impact to be Applied in Specimen Preparation & & $2 \times 50$ & $2 \times 50$ & TS EN 12697-30 \\
\hline Air Voids (\%) & & $2-4$ & - & TS EN 12697-8 \\
\hline Air Voids in Hot Climate Regions (\%) & & $3-4$ & & \\
\hline \multirow[t]{2}{*}{ Voids in mineral aggregate (VMA) (\%) min } & Type-1 & 16 & 13 & TS EN 12697-8 \\
\hline & Type-2 & 17 & & \\
\hline \multirow[t]{2}{*}{ Bituminous binder (\%) $\min$} & Type-1 & 5.8 & 5.2 & TS EN 12697-1 \\
\hline & Type-2 & 6.5 & & \\
\hline Fiber content $(\%)$ & & $0.3-1.0$ & $0.2-0.8$ & - \\
\hline
\end{tabular}

Sample Preparation. The mixing temperature of conventional SMA design is the temperature the bitumen is heated at temperature about $170{ }^{\circ} \mathrm{C}$ to obtain a certain fluid. The mixture temperature is given in the specification. The SMA mixture preparation temperature is produced at higher temperatures than the conventional HMA. The reason for this high temperature is to prevent the fibers that will be involved in competing from lowering the workability of the mixture. Fiber additives only exhibit less viscous structure under high temperatures. In this study, standard SMA Marshall design steps were followed for samples prepared with normal bitumen, while for SMA to be prepared with WMA additives, mixture temperatures specified in manufacturer catalogs were applied especially at mixture temperatures.

Firstly, Marshall specimens were prepared for 50/70 bitumen as a control mixture. After that, Marshall specimens were prepared with the modified bitumens which were produced by adding $A 1, A 2$, and $A 3$ at the rates of $0.3 \%, 3.0 \%, 0.4 \%$ of bitumen weight according to producers' technical sheets respectively.

When designing SMA, depending on the traffic load, 50 blows are applied to both surfaces of the specimens to be compacted. The cylindric test specimens, cooled down to room temperature, was removed from the molds with the help of a sample extractor rack and kept at the laboratory temperature for 24 hours. 
Marshall Test Results. To calculate the optimum bitumen percentage, graphs of practical specific gravity, flow, stability, void (Va), voids filled with asphalt (VFA), voids in mineral aggregates (VMA) of samples prepared in different bitumen fractions are plotted. When determining the optimum percentage of bitumen, the value of voids is usually taken into account for between $4 \%$ to $5 \%$ voids for the binder coarse according to Turkish Highways Specifications (Turkey General Directorate of Highways, 2013). Other values based on the voids value must conform to the specification criteria given in Table 1. The Marshall results obtained are summarized in Table 4.

Table 4. Marshall Test Results, Source: Self-elaboration.

\begin{tabular}{lcccc} 
Parameters & SMA Asphalt & A1 & A2 & A3 \\
\hline Stability (Kg) & 757 & 238 & 527 & 522 \\
Flow (mm) & 3.30 & 3.27 & 3.43 & 3.43 \\
Air Voids (\%) & 3 & 3 & 3 & 3 \\
Air Voids in Hot Climate Regions (\%) & & & 85.3 \\
Voids filled with asphalt (VFA) (\%) & 85.7 & 85.3 & 86.1 & 21.1 \\
Voids in mineral aggregates (VMA) (\%) & 19.3 & 21.3 & 20.3 & 2.72 \\
Volumetric specific gravity (g/cm 3$)$ & 2.46 & 2.43 & 2.43 & 7.7 \\
Optimum Bituminous rate (\%) & 6.9 & 7.7 & 7.8 & 0.35 \\
Fiber Amount (\%) & 0.35 & 0.35 & 0.35 & 155 \\
Mixing Temperature $\left({ }^{\circ} \mathrm{C}\right)$ & 170 & 155 & & 155 \\
\hline
\end{tabular}

Optimum Bitumen Percentages. The optimum bitumen ratios were determined according to the void ratio given in Figure 2. According to the results obtained, each of the additives used resulted in an increase in the optimum bitumen ratio. This increase in the optimum bitumen ratio can be a disadvantage in terms of cost.

Figure 2. Optimum Bitumen Percentages, \%. Source: Self-elaboration.

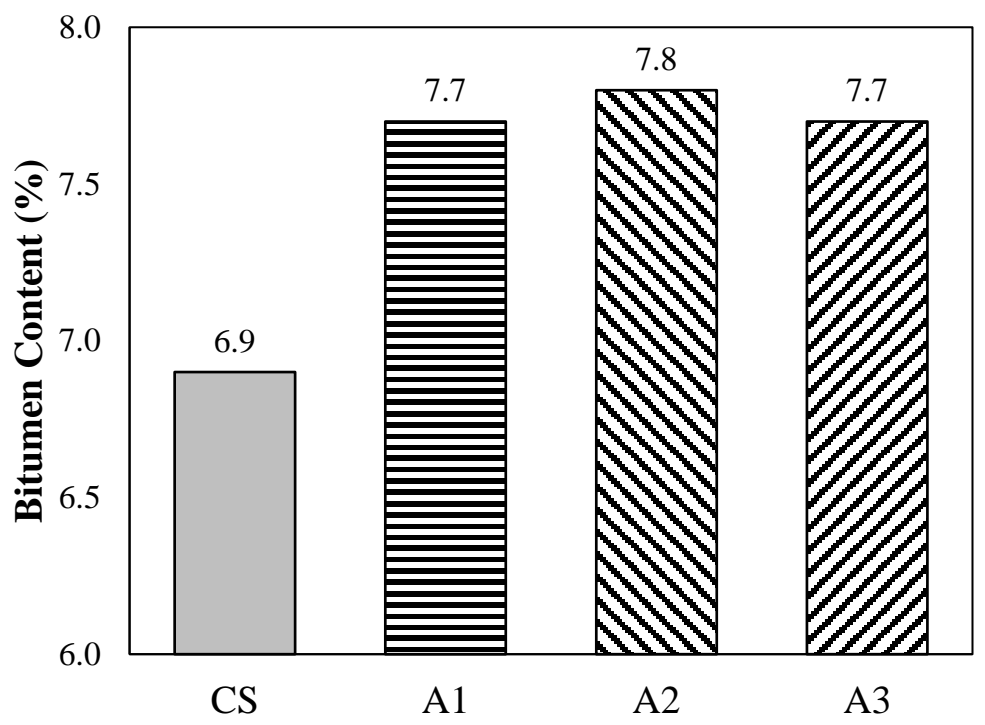

Stability. The stability results are given in Figure 3. The results show that the additives reduced the stability. However, according to the Technical Specifications for the Highways (TSH), the stability of the SMA design is not considered. As a result, it is expected that the additives used for the bitumen modification in the SMA design according to TSH will decrease the stability.

Flow: As seen in Figure 4, the WMA admixtures used in this study generally showed higher flow values than the control sample (CS). According to these results, it can be said that the WMA admixtures form a SMA mixture exhibiting more plastic behavior. However, considering the yield values corresponding to the optimum bitumen ratios found for each mixture, it can be seen that the A1 addition decreases the flow value and the other additives increase the flow value compared to the control mixture. 

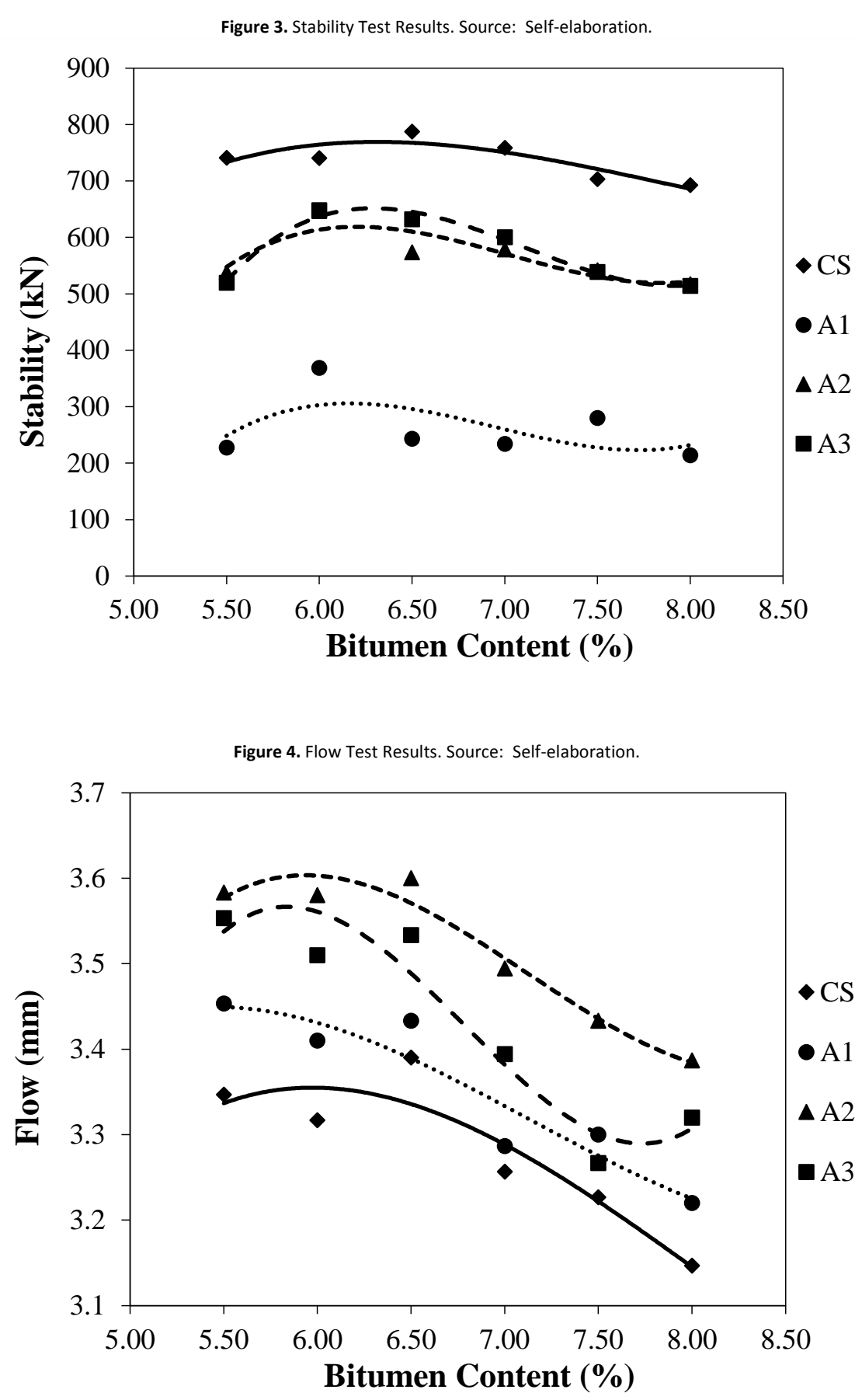

Air Voids: As shown in Figure 5, each of the WMA admixtures increased air voids. Considering the optimum bitumen results, it can be observed that the WMA additives increase air voids compared to the control mixture.

Voids filled with asphalt (VFA): As seen in Figure 6, it has been observed that the WMA additives generally lower the VFA value for the SMA design. However, when the VFA values are compared with the optimum bitumen values obtained for each additive, it can be observed that only the A2 additive increases the VFA value by some amount. 

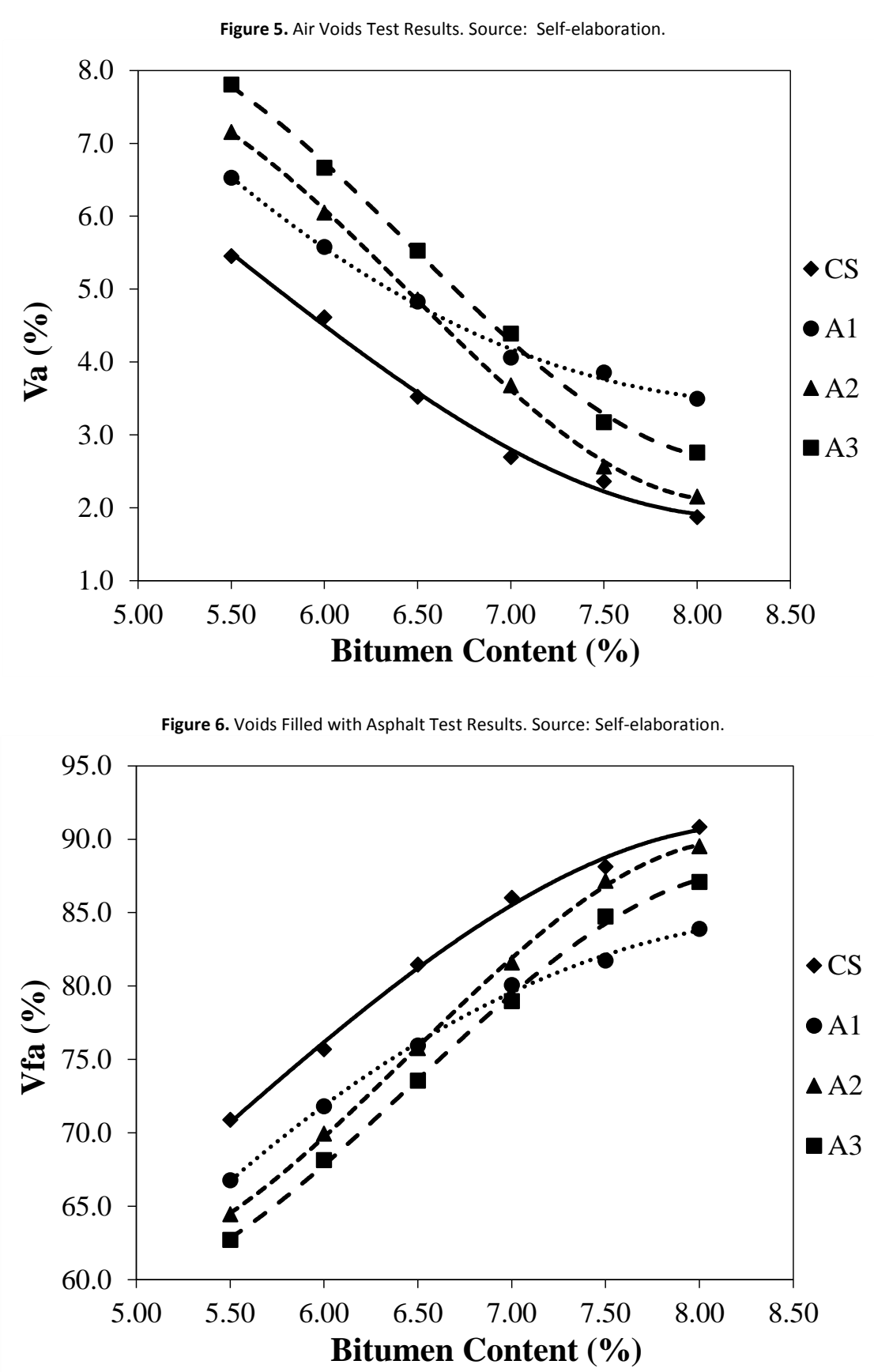

Voids in mineral aggregates (VMA). As shown in Figure 7, each of the WMA additives is over the minimum $16 \%$ VMA value, which is defined in the specification value for SMA Type-1. All of the additives increased the value of VMA. It can also be said that the additives reduce the VMA value within the optimum bitumen results.

Volumetric Specific Gravity. As it is shown in Figure 8, it appears that the additives generally reduce the specific gravity of the mixture. In addition, according to the optimum bitumen results, A1 and A2 reduced the specific weight of the mixture by a small amount while $A 3$ increased the specific weight of the mixture by $10 \%$ on average. 


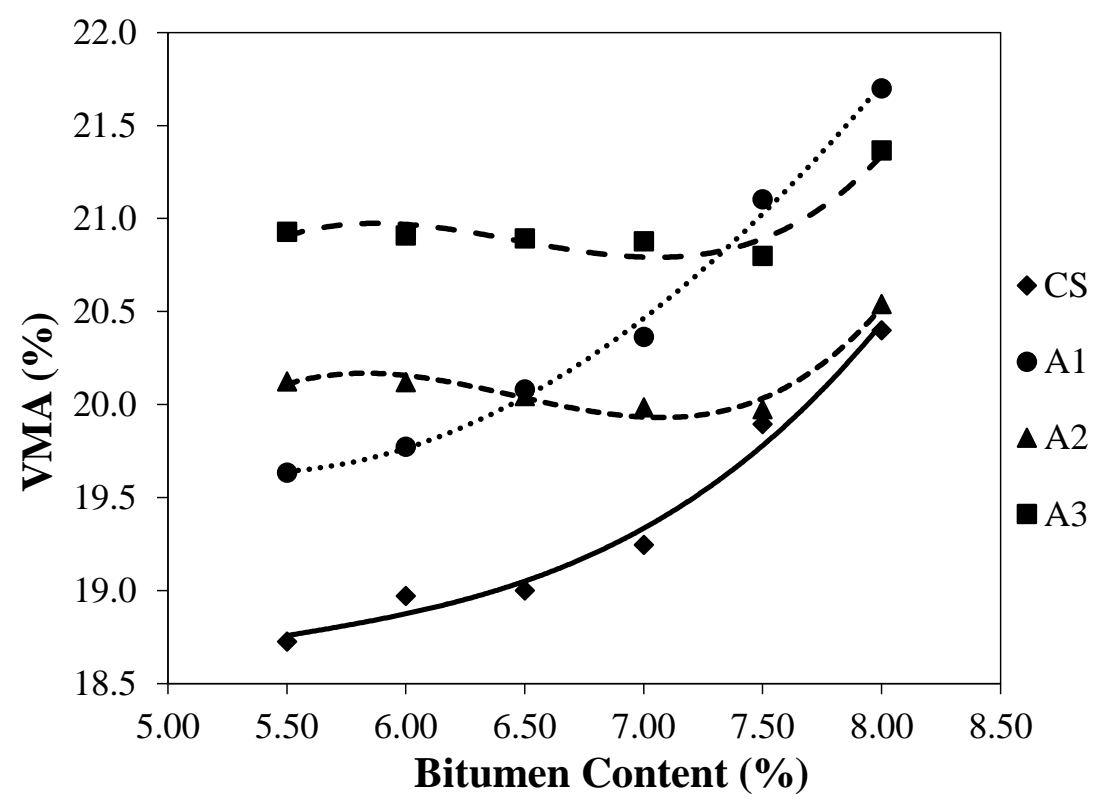

Figure 8. Volumetric Specific Gravity Test Results. Source: Self-elaboration.

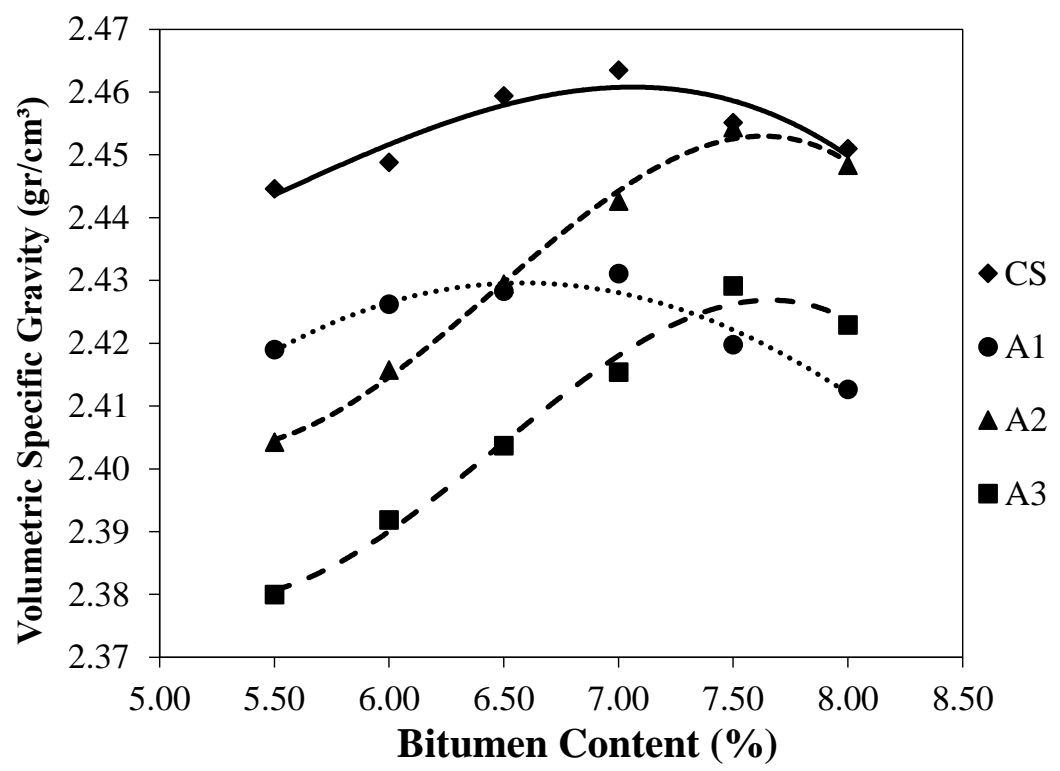

Results and conclusion

Effect of various WMA additives on SMA design parameters was investigated and results derived from the experimental study were compared with the control samples. According to the results of the WM-SMA Marshall tests, each of the additives reduced the SMA stability and increased the flow value within the specification limits. All additives increased the voids in mineral aggregates (VMA) and the voids filled with asphalt (VFA) of the mixtures, while the other additives reduce them. It was observed that WM-SMA prepared according to the manufacturer's catalog with the WMA additives lowered the mixing temperature by about $15^{\circ} \mathrm{C}$. This decrease in the mixture temperature means fuel savings and less harmful gas release during production in the asphalt plant. At the same time, each of the additives used has increased the percentage of optimum bitumen, which can be economically disadvantageous. It can be economically more advantageous in the long period by reducing the fuel consumption and the efficiency of the mix, and by allowing the mix to operate at wider season intervals with increased workability even at low temperatures, and most importantly by reducing the environmental impact. It is also possible to say that the use of WMA additives is highly advantageous for SMA production, which requires high heat while production and compaction. 
Asphalt_Innovations. (2010). Product Data Bulletin. North Charleston.

Chowdhury, A., \& Button, J. W. (2008). A Review of Warm Mix Asphalt. Report, Texas A\&M University System College Station, Texas Transportation Institute.

Clariant. (2018). Licomont BS 100 powder. Retrieved July 1, 2018, from https://www.clariant.com/en/Solutions/Products/2014/03/18/16/33/Licomont-BS-100-powder

Dubravský, M., \& Mandula, J. (2015). Modified Asphalt Binder with Natural Zeolite for Warm Mix Asphalt. Selected Scientific Papers - Journal of Civil Engineering, 10(2). https://doi.org/10.2478/sspjce-2015-0018

Hafeez, I., Kamal, M. A., \& Mirza, M. W. (2015). An experimental study to select aggregate gradation for stone mastic asphalt. Journal of the Chinese Institute of Engineers, 38(1), 1-8. https://doi.org/10.1080/02533839.2014.953242

Istanbulteknik. (2018). Pawma Warm Mix Asphalt Additive. Retrieved July 7, 2018, from https://www.istanbulteknik.com/en/asphalt-products/pawma-warm-mix-asphalt-additive

Khedmati, M., Khodaii, A., \& Haghshenas, H. F. (2017). A study on moisture susceptibility of stone matrix warm mix asphalt. Construction and Building Materials. https://doi.org/10.1016/j.conbuildmat.2017.03.121

Kim, Y., Lim, J., Lee, M., Kwon, S., Hwang, S., \& Lee, J. (2015). Comprehensive Evaluation of Warm SMA Using Wax-Based WMA Additive in Korea. Journal of Testing and Evaluation, 43(5). https://doi.org/10.1520/Jte20130144

Kok, B. V, \& Akpolat, M. (2015). Effects of Using Sasobit and SBS on the Engineering Properties of Bitumen and Stone Mastic Asphalt. Journal of Materials in Civil Engineering, 27(10). https://doi.org/Artn 0401500610.1061/(Asce)Mt.1943-5533.0001255

Kok, B. V, Yilmaz, M., \& Erkus, Y. (2017). Effects of Graphite on Mechanical Properties of Stone Mastic Asphalt Pavement. Journal of Civil Engineering and Management, $1013-1020$. https://doi.org/10.3846/13923730.2017.1374302

Leng, Z., Al-Qadi, I. L., \& Cao, R. (2017). Life-cycle economic and environmental assessment of warm stone mastic asphalt. Transportmetrica A: Transport Science, 1-14. https://doi.org/10.1080/23249935.2017.1390707

Oluwasola, E. A., \& Hainin, M. R. (2016). Evaluation of Performance Characteristics of Stone Mastic Asphalt Incorporating Industrial Waste. Journal of Materials in Civil Engineering, 28(12). https://doi.org/Artn 0601601610.1061/(Asce)Mt.1943-5533.0001595

Turkey General Directorate of Highways. (2013). Highways technical specification. Ankara, Turkey.

Valdés, G., Miró, R., \& Martínez, A. (2015). Assessment of the adhesive capacity of asphalt binders in the aggregatebinder bonds by means of new methodology. Revista de La Construcción. Journal of Construction, 14(1), 69-76. Retrieved from http://revistadelaconstruccion.uc.cl/index.php/rdlc/article/view/479

Valdés Vidal, G., Calabi-Floody, A., \& Sanchez-Alonso, E. (2017). Evaluation of the durability of asphalt mixtures depending on the physical properties of aggregates. Revista de La Construcción, 16(1), 92-103. https://doi.org/10.7764/RDLC.16.1.92

Vázquez, V., Terán, F., Luong, J., \& Paje, S. (2019). Functional Performance of Stone Mastic Asphalt Pavements in Spain: Acoustic Assessment. Coatings. https://doi.org/10.3390/coatings9020123

Wasilewska, M. (2017). Evaluation of Skid Resistance of Wearing Course Made of Stone Mastic Asphalt Mixture in Laboratory Conditions. World Multidisciplinary Civil Engineering-Architecture-Urban Planning Symposium Wmcaus, 245. https://doi.org/Unsp 02204310.1088/1757-899x/245/2/022043

Woodward, D., Millar, P., Lantieri, C., Sangiorgi, C., \& Vignali, V. (2016). The wear of Stone Mastic Asphalt due to slow speed high stress simulated laboratory trafficking. Construction and Building Materials, 110, $270-277$. https://doi.org/10.1016/j.conbuildmat.2016.02.031 